\title{
Review Article \\ How to Improve the Survival of Transplanted Mesenchymal Stem Cell in Ischemic Heart?
}

\author{
Liangpeng Li, ${ }^{1}$ Xiongwen Chen, ${ }^{2}$ Wei Eric Wang, ${ }^{1}$ and Chunyu Zeng ${ }^{1}$ \\ ${ }^{1}$ Department of Cardiology, Daping Hospital, Third Military Medical University, 10 Changjiangzhilu Road, Chongqing 400042, China \\ ${ }^{2}$ Cardiovascular Research Center, Temple University School of Medicine, Philadelphia, PA 14190, USA
}

Correspondence should be addressed to Wei Eric Wang; weiericwang@163.com and Chunyu Zeng; chunyuzeng100@163.com

Received 17 April 2015; Accepted 18 June 2015

Academic Editor: Luca Vanella

Copyright (c) 2016 Liangpeng Li et al. This is an open access article distributed under the Creative Commons Attribution License, which permits unrestricted use, distribution, and reproduction in any medium, provided the original work is properly cited.

\begin{abstract}
Mesenchymal stem cell (MSC) is an intensely studied stem cell type applied for cardiac repair. For decades, the preclinical researches on animal model and clinical trials have suggested that MSC transplantation exerts therapeutic effect on ischemic heart disease. However, there remain major limitations to be overcome, one of which is the very low survival rate after transplantation in heart tissue. Various strategies have been tried to improve the MSC survival, and many of them showed promising results. In this review, we analyzed the studies in recent years to summarize the methods, effects, and mechanisms of the new strategies to address this question.
\end{abstract}

\section{Introduction}

Ischemic heart disease is the leading cause of death worldwide. Severe ischemic heart disease, especially myocardial infarction (MI) and heart failure, causes a significant loss of functional cardiomyocytes [1]. However, heart is an organ with very limited self-renewal capacity because adult cardiomyocytes can hardly regenerate [2]. Over the past decades, there has been tremendous enthusiasm in an attempt to repair cardiac tissue with stem cell transplantation [3]. Mesenchymal stem cell (MSC), with advantages in immunologic privilege, easy to be acquired, and multilineage potential, has been widely studied both in animal model and in clinical trials [4]. Low survival rate after transplantation is one of the crucial reasons accounting for the hampered cardiac repair effect of MSC. The harsh microenvironment with ischemia, inflammation, oxidative stress, and mechanical stress contributes to the great cell loss. Hence, a number of strategies have been used in attempt to overcome this obstacle. In this review, we summarize the advance of these strategies recently reported.

\section{Characterization of MSC}

MSCs are generally described as nonhematopoietic subpopulation of cells with multilineage potential to differentiate into various tissues of mesodermal origin [5]. MSCs were first identified and isolated from bone marrow (BM) more than 40 years ago [6]. They can also be isolated from other sources, such as adipose [7], synovial tissue [8], lung [9], umbilical cord blood [10], peripheral blood [11], and olfactory bulbs [12], or even in virtually all postnatal organs and tissues [13]. Among these, the most frequently used MSCs in studies for cardiac repair are BM-derived MSC (BM-MSC) and adiposederived MSC (ADSC).

MSC has been proven to differentiate into osteoblasts, chondrocytes, and adipocytes [14]. It is also reported that MSC can transdifferentiate into mesodermal derived cell types including cardiomyocyte $[15,16]$, but the cardiogenic potential of MSCs is still controversial $[17,18]$.

MSCs are fairly heterogeneous cell population but lacks a specific marker to define MSCs [19]. According to minimum criteria that were proposed by The International Society for Cell Therapy in 2006, MSCs are characterized as (1) adherence to plastic in standard culture conditions; (2) expressing surface molecules CD73, CD90, and CD105, but in the absence of $\mathrm{fCD} 34$, CD45, HLA-DR, CD14 or CD11b, CD79a, or CD19; (3) a capacity for differentiation to osteoblasts, adipocytes, and chondroblasts in vitro [20]. Besides, MSCs possess species-specific characteristics [21], and the characteristics of MSCs may also vary according to the source of 
tissue [22]. For example, ADSCs were superior to BMSC with respect to maintenance of proliferating ability [23].

\section{MSC Transplantation for Treating Ischemic Heart Disease}

The first study exploring the cardiac regenerative effect of MSC was carried out in 1999 on a rat MI model induced by cryoinjury [24]. The autologous MSC was induced into cardiogenic cells by 5-azacytidine in vitro and transplanted into the scar of the injured hearts. The transplantation improved cardiac function, prevented remodeling, and promoted angiogenesis. In the following decades, MSCs were transplanted for treating chronic or acute ischemic heart injury in rodent models and large animals. The underlying mechanisms for the therapeutic effect include directly transdifferentiation into functional cardiomyocyte/endothelial cell, secretion of a broad spectrum of cytokine in a paracrine manner, and stimulating local cardiac stem cell proliferation [25]. It was reported that MSC can differentiate into cardiomyocyte phenotype induced by 5-azacytidine [26], coculture [15], and in vivo [16] models. Some observed that MSCs transdifferentiate into cardiomyocyte in vivo, but the cardiogenic potential of MSCs remains highly controversial. Fazel et al. injected MSCs from $\beta$-galactosidase ( $\beta$-gal) transgenetic mice into the injured ischemic myocardium. As a result, there was no $\beta$-gal positive cardiomyocyte observed 28 days after transplantation in recipient hearts, indicating that the transdifferentiate ability of MSCs is lacking [27]. Noiseux et al. found a very few MSC-derived cardiomyocytes after transplantation, but nearly all of which were demonstrated to result from cell fusion [18]. Thus it seems that paracrine function but rather cardiogenic transdifferentiation predominantly accounts for the therapeutic effect of MSC transplantation [28].

Paracrine function of MSCs results from the MSC secretion of antiapoptotic, proangiopoietic factors (growth factors, cytokines, surface molecules, mRNA, miRNA, and exosomes) [29]. Several growth factors which consisted in conditioned medium, such as VEGF [30], FGF [31], IGF, and HGF [32], also showed cardiac regenerative capability when applied to MI model. Exosomes (or microvesicle) secretion by transplanted MSCs was reported by increasing studies [33]. Exosomes are cholesterol-rich, phospholipid vesicles of 30-100 nm enriched with microRNAs (miRNAs). MSCsderived miRNAs-bearing exosomes are readily internalized into cardiomyocyte or and endothelial cell, resulting in cardioprotective effect via angiogenetic, antiapoptotic, or anti-inflammatory effect. MSC exosomes transferring miR-22 (can target methyl CpG binding protein 2) [34] and miR-221 (can inhibit p53-upregulated modulator of apoptosis) [35] reduce cardiomyocyte apoptosis. MSC exosomes can also reduce neutrophil and macrophage infiltration after myocardium ischemic/reperfusion injury [36].

Mitochondria transferring between MSCs and neighboring somatic cells via a "tunneling nanotube" (TNT), composed of partial membrane fusion and F-actin, was reported. This process rescued aerobic respiration of cells harboring mitochondria damage [37]. MSC also showed capacity to convey functional mitochondria to connected cardiomyocyte via TNT [38]. In a human MSCs-mouse adult cardiomyocyte coculture system, heterogeneous partial cell fusion by "tunneling nanotube" junction formation has been observed. These partial fused cells exhibited a progenitor cell-like phenotype or were described as "reprogramming/dedifferentiation." The mitochondria conveyed through TNT were necessary for the transient partial fusiondependent cardiomyocyte reprogramming [38]. Although the in vivo evidence of TNT formation and mitochondria transfer between MSC and cardiomyocyte were lacking, these findings suggested an alternative mechanism for MSC mediated beneficial effect.

Despite the underlying mechanism which remains to be clarified, the established cardioprotective effect of MSC therapy has been confirmed by most preclinical studies. In 2001, the first clinical trial of BMSCs transplantation on MI patient was conducted [39]. Thereafter, a large number of phase I/II clinical trials were designed to test the safety, feasibility, and efficiency of MSC therapy [40]. A phase II/III trial with 80 patients enrolled was conducted recently [41]. Overall, the safety and feasibility profiles of MSC therapy have been well established by most of the trials followed from 1 month to 2 years, such as POSEIDON [42], C-CURE [43], TACHFT [44], and MSC-HF [45]. The efficacy is also suggested, as observed improvement in $6 \mathrm{~min}$ walk (POSEIDON, CCURE, and TAC-HFT), EF (C-CURE, MSC-HF), Minnesota Living with Heart Failure Questionnaire (MLHFQ) (POSEIDON, TAC-HFT), event-free survival in a 2-year followup (C-CURE), and reduced LV chamber (POSEIDON, CCURE, and MSC-HF), and scar size (POSEIDON). Moreover, POSEIDON proved that allogenic MSC is comparable to autologous MSC without significant alloimmune reactions [42], supporting a favorable feasibility for MSC therapy; in addition to improved EF, a reduction in ventricular arrhythmias and improved pulmonary function were also reported in the trial employing MSC to treat patients with acute MI [46]. However, to confirm the efficacy of MSC therapy, especially the long-term outcome in patient, more rigorously designed, multicenter, long-term follow-up, well-interpreted trials with larger sample size are required. Although most of these trials have demonstrated that MSC therapy in clinical trials appears to be safe and effective [47], there are also reported investigations without observed benefits of MSC application [41]. According to the systematic review reported by Lunde et al., the MSC therapy had moderate beneficial effect on improving cardiac function (LVEF increased by $2.99 \%$ on average [48]) and limited effects on long-term effect or global end point [49].

\section{Poor MSC Survival and Its Mechanisms}

4.1. MSC Survival in Animal Model of MI. Among the factors which hurdle the therapeutic effect of MSC treatment, the poor survival after cell transplantation is a crucial one. Positron emission tomography (PET) tracking of MSC delivered by catheter-based transendocardial injection showed retention of approximately $6 \%$ of injected cells in porcine ischemic myocardium at 10 days after injection [50]. Toma 
et al. reported that less than $0.44 \%$ of MSCs survived by day 4 after engraftment in immunodeficient mouse hearts [16]. Accordingly, approximate $1 \%$ of MSCs were detected 24 hours after transplantation in rat heart with experimental MI [51].

4.2. MSC Survival in Ischemic Human Heart. Clinical trials have consistently demonstrated that the retention and survival of stem cells are quite low after transplantation into infarcted heart. In a small group of STEMI patients, intracoronary infusion of BMSCs labeled with 18F-FDG showed minimal retention in the infarct region $(1.3 \%$ to $2.6 \%$ ) when imaged by PET at 50-75 minutes after cell injection [52]. Intracoronary infusion of cultured peripheral mononuclear cells labeled with ${ }^{111}$ Inoxine in patients with recent STEMI resulted in activity of $6.3 \pm 2.9 \%$ in the heart $24 \mathrm{~h}$ after injection, but it declined to $2.1 \%$ when measured 2 days later [54].

Considering that the acute MI can cause over one billion cardiomyocyte losses, one cannot realistically expect a clinically meaningful benefit from such a tiny number of residual donor cells [55]. This may account for the modest improvement of cardiac function reported in clinical trials.

4.3. Mechanisms for the Poor Survival of Transplanted MSC. The loss of cells number occurs in several ways: (1) a mechanical leakage of cells immediately after injection was due to the continuous compressive mechanical stress; (2) cell death, including both necrosis and apoptosis, was subsequently worsened by a harsh microenvironment of hypoxia, inflammation, and oxidative stress comprising superoxide anions and hydrogen peroxide [56]; (3) gradual loss is also attributed to the limited self-renewing rate of stem cell in ischemic myocardium, due to the lack of oxygen, inadequate nutrients, and the disrupted extracellular cell matrix (ECM).

\section{Strategies to Improve MSC Survival}

Several strategies have been explored to augment the longevity of engrafted cells in the hostile ischemic environment. The strategies are (1) more effective ways of delivery; (2) tissue engineering strategies involving scaffolds made of natural or synthetic polymers; (3) preconditioning of MSC before transplantation; (4) genetic manipulation of MSCs; (5) combined administration of MSC with another cell type or medicine.

5.1. Delivery Route. Stem cell can be delivered to myocardium through different ways, including peripheral intravenous infusion, direct surgical injection during open heart surgery, catheter-based intracoronary infusion, retrograde coronary venous infusion, and transendocardial injection [57, 58]. Using $\gamma$-emission counting of harvested organs 1 hour after cell delivery, it has been demonstrated that intramyocardial injection had the highest retention rate of delivered BMSCs. Significantly more cells were retained after intramyocardial injection $(11 \pm 3 \%)$ compared with intracoronary $(2.6 \pm$ $0.3 \%)$ and interstitial retrograde coronary venous infusion $(3.2 \pm 1 \%)$. Intramyocardial injection is the most frequently reported route for MSC therapy in animal studies, but most of the clinical trials applied catheter-based intracoronary infusion.

However, there are still some disadvantages along with needle-injection: (1) a washout of cells through channel leakage and the vascular system; (2) an inhomogeneous distribution of cells [59]. To overcome these obstacles, a cell sheet/patch based delivery method has been developed. Confluent, intact cell layers (usually 2 to 3 layers) with abundant ECM and cell-cell interaction can be acquired by culturing MSCs in thermosensitive dishes or fibrin-coated culture plate (confluent cell sheet detached spontaneously at room temperature within 30 minutes), several weeks after MI. The cell sheet was deposited onto the infarcted myocardium, and the MSC can be engrafted into myocardium and the sheet was absorbed gradually [55]. In rat model of MI, two months after the implantation, the three-layer ADSC sheet showed superior effect of cell retention compared with isolated ASDC delivered by intramyocardial injection [60].

5.2. Biomaterials. Due to the disrupted ECM and compressive mechanical stress, the infarcted myocardium is not an environment conducive to cell survival. Therefore, cardiac tissue engineering emerged as a promising strategy, and three-dimensional polymeric scaffolds for stem cells were developed. Scaffolds temporarily provide the biomechanical support for cells until they are able to produce their own extracellular matrix [61-63]. Scaffolds seeded with MSC showed better performance in cardiac repair than injection of MSC alone [64]. There are mainly two types of scaffold.

5.2.1. Thermosensitive Hydrogel. Hydrogel as a biocompatible material was used to prevent the first wave loss of transplanted MSC due to the myocardium contraction. Hydrogels are in situ formation, biodegradable, and cell adhesive. Once delivered together with MSC, it can self-cross-link to form semigrid scaffold which could ameliorate the cell loss.

There are various types of hydrogels applied in MSC therapy for MI: (1) natural hydrogels, such as fibrin glue [65], collagen [66], alginate [67], and cardiogel [68]; cardiogel is a cardiac fibroblast-derived ECM, which was designed to mimic the natural environment suitable for transplanted MSC [68]; (2) synthetic hydrogel, including silanized hydroxypropyl methylcellulose (Si-HPMC) [69] and poly(lactideco-epsilon-caprolactone) [64]; (3) combination of different materials in a certain ratio, such as poly $(\mathrm{N}$-isopropylacrylamide) (PNIPAAm) plus single-wall carbon nanotubes (SWCNTs) [70], alginate/chitosan [71], poly(glycerol sebacate) combined with collagen [72], and hydrophobic poly $(\varepsilon-$ caprolactone)-2-hydroxylethyl methacrylate (PCL-HEMA) plus PNIPAAm [73]. Hydrogel can also serve as a medium to support the diffusion of molecules [74]. Since interleukin10 (IL-10) is an anti-inflammation cytokine, a combination of MSC, Matrigel, and IL-10 plasmids was designed to improve cell survival [75].

Hydrogel is effective in improving cell survival in stem cell therapy. In a rat MI model, intramyocardial injection of MSCs with Si-HPMC (one of the synthetic hydrogels) showed 
better performance in cell retention and cardiac function preservation than MSCs injection alone [76]. In a swine MI model, retention of MSC suspended in 2\% alginate (a natural hydrogel) before transplantation was approximately 4 -fold compared to that in control MSCs at two weeks after delivery [77]. Similarly, coinjection with fibrin glue increased ADSC survival by about $30 \%$ on a rat MI model [78].

The first clinical trial using injectable bioabsorbable scaffold (IK-5001), a solution of $1 \%$ sodium alginate plus $0.3 \%$ calcium gluconate, combined with MSCs by intracoronary delivery has been carried out (http://www.clinicaltrials.gov.: NCT01226563). This first-in-man pilot study also showed that intracoronary deployment of an IK-5001 scaffold is feasible, effective, and well tolerated in patients with STEMI [79].

5.2.2. Patch/Cell Sheet. To avoid the shortcomings of needle injection, biocompatible patches seeded with MSC emerged as an alternative strategy to circumvent the lack of cell engraftment. Solid form of biomaterials (such as collagen) seeded with cells was sutured onto the surface of infarcted area. The patch can be absorbed gradually while the stem cells engrafted into the myocardium.

ADSC-cellularized sheets were implanted onto the epicardium of on chronic rat MI model [80]. No cell was detected in ADSC alone group, but cell sheet exhibited $25.3 \pm 7.0 \%$ and $6.4 \pm 4 \%$ engraftment rate at 1 week and 1 month after MI $[60,80]$. The same group performed a head-to-head comparison of cell engraftment between the conventional injection, deposition of the bilayer myoblast cell sheet, and deposition of the myoblast cells seeded in collagen sponge in rat MI model. Both cell constructs are superior to conventional needle injection. The myoblast-seeded collagen sponge group produced the best outcome with regard to engraftment cells number and reduced fibrosis [55].

\subsection{Hypoxic, Hyperoxic, and Pharmacological Preconditioning} of MSCs. Although severe hypoxia can lead to cell death, repeated episodes of short period exposure to hypoxia (hypoxia-preconditioning) have shown conferring cytoprotective benefits [81]. Usually, MSCs were cultured under hypoxia ( $0.5 \%$ oxygen) or normoxic conditions for 24 hours: hypoxia-preconditioning reduced about $25 \%$ of cell death at day 1 and $40 \%$ of cell death at day 3 after delivery compared with normoxic control [82]. This effect is associated with the increased expression of prosurvival and proangiogenic factors including hypoxia-inducible factor 1 (HIF-1 $\alpha$ ), angiopoietin-1, vascular endothelial growth factor (VEGF), erythropoietin, Bcl-2, and Bcl-xL [82]. Moreover, hypoxiapreconditioning induced autophagy protected MSC from apoptosis, which may be also accounted for the improvement of MSC survival [83].

On the other hand, preconditioning with hyperoxia (100\% oxygen) or/and Z-VAD-FMK pan-caspase inhibitor promoted MSCs viability and proliferation, by decreasing caspases $1,3,6,7$, and 9 expression and increasing survival genes such as Akt [84].

Sevoflurane, an inhaled anesthetic widely used in clinical anesthesia, has similar effect of hypoxia-preconditioning.
Sevoflurane pretreatment minimized MSC apoptosis and the loss of its mitochondrial membrane potential induced by hypoxia, which may be mediated by HIF and Akt pathways [84].

Study also revealed that MSCs for transplantation could be preconditioned by coculturing with cells. MSC preconditioned with cardiomyocytes in culture exerted enhanced therapeutic effect compared with MSC alone [85]. The hetero-cell-to-cell connection altered the MSC paracrine of cardioprotective soluble factors such as VEGF, HGF, SDF- $1 \alpha$, and MCP-3.

Preconditioning of MSCs with TGF- $\alpha$ enhanced the VEGF secretion of transplanted MSC in vivo, thereby enhancing MSCs' ability to protect myocardium from IR injury [86]. Platelet-derived growth factor-BB (PDGF) treatment of MSCs resulted in rapid activation of both Akt and ERK and upregulated VEGF. Thus, MSCs with PDGF preconditioning exhibited a greater capacity of functional recovery compared with naïve MSCs in I/R injured heart [87].

Preconditioning can be operated in vitro prior to transplantation, which circumvents the side effect caused by other approaches such as genetic manipulation. Since the forced gene manipulation in stem cells raises concern about the safety in long-term effect, the continuous overexpression of gene in MSCs may be harmful if the microenvironment switches to different stage [88].

5.4. Genetic Modification of MSCs. Genes related to cardiac protection from I/R injuries such as Akt and Integrin-linked kinase [89] and genes involved in apoptosis such as Bcl-2 [90] promoted stem cell survival in ischemic myocardium.

Akt has been well documented among genetic approaches. In both rat and porcine model of MI, transplantation of Akt-engineered MSCs led to improved LVEF and reduced scar size and fibrosis; this is because not only were Aktengineered MSCs more resistant to apoptosis [18, 91], Akt modification also enhanced MSC secretion of paracrine factors such as VEGF, IGF-1, and FGF-2 [92]. A double overexpression system in MSCs comprising Akt and angiopoietin-1 (an important modulator in angiogenesis) further improved cell survival [93]. Overexpression of heat shock protein 20 (Hsp-20) [94], secreted frizzled related protein 2 (sFRP2), a modulator of the Wnt signaling [95], survivin [96], heme oxygenase (HO-1) [97], GSK-3 $\beta$ [98], ERBB4 [99], CCR-1 [100], and serum derived factor-1 (SDF-1) [101] in MSC had similar beneficial effect on cell survival.

We have demonstrated previously that silencing of prolyl hydroxylase domain protein 2 (PHD2) enhanced ADSC survival after transplantation into murine ischemic myocardium, by maintenance of active HIF-1 $\alpha$ [102]. PHD2 silencing can also enhance ADSC paracrine antiapoptotic effect on cardiomyocytes against ischemia via NF- $\kappa$ B signaling. Similarly, GATA-4 overexpression in MSCs increased both MSC survival and angiogenic potential in ischemic myocardium [103].

In addition to coding gene, microRNA (miR) has been explored for stem cell therapy with its multitargets property. Overexpression of miR-1 in MSCs promoted their survival 2-3-fold at 7 days after transplantation, leading to more 
conducive repair of infarct injury and improved heart function. miR-1 promoted MSC survival via regulating caspase 9, Bcl-2, and Bax [104]. miR-210 engineering has similar effect in MSCs through antioxidative c-Met pathway [105].

5.5. Cotransplantation of MSCs with Other Cells. CS/PCs, such as c-kit positive residential progenitor cells in heart [106], emerged as another potential cell source for cardiac repair [106]. Clinical trial of CS/PCs reported encouraging results in preserving cardiac function for patients with ischemic cardiomyopathy [107]. Based on the observation that MSC can stimulate endogenous CS/PCs proliferation [25] and regulate CS/PCs niches [108], studies have been performed to explore the effect of using MSCs together with CS/PCs $[109,110]$. In a porcine model of MI, a combination of human CS/PCs and MSCs labeled with iron oxide for CMR imaging was delivered into myocardium 14 days after MI. CMR revealed that this combination was 7-fold greater cell engraftment than either cell type alone, thereby further reduced scar size, and improved cardiac function [110].

Inflammatory status in acute stage is another important factor causing the low retention of transplanted MSCs. Previous studies have shown that $\mathrm{CD} 4{ }^{+} \mathrm{CD} 25^{\text {hi }} \mathrm{FoxP}^{+}{ }^{+} \mathrm{T}$ regulatory (Treg) cells have a potential to suppress inflammation, thus providing a favorable environment for MSC engraftment $[53,111]$. The cotransplantation of autologous Treg cells with MSC dramatically increased the MSC survival rate and proliferation in a porcine MI model with no deleterious side effects observed [112].

5.6. Administration of MSCs with Medication. Statins have some cardioprotective function independent of their lipid-lowering ability. They can protect endothelial function, increase nitric oxide bioavailability, and exert antioxidant/anti-inflammatory effects [113-117]. Combination of Simvastatin $(0.25 \mathrm{mg} / \mathrm{kg} / \mathrm{d})$ and MSC transplantation $\left(3 \times 10^{7}\right.$ cells per animal $)$ showed approximately 4 -fold higher MSC survival rate compared with MSC alone. This was due to the fact that oxidative stress and inflammatory response were significantly reduced in the infarcted regions by Simvastatin [118]. Other groups reported that Rosuvastatin improved survival of ADSCs after transplantation into infarcted hearts. Improved cardiac function and reduced fibrosis were observed in Rosuvastatin plus ADSC group. Bioluminescence imaging and histological staining in vivo revealed that Rosuvastatin ( $20 \mathrm{mg} / \mathrm{kg}$ per day for 28 days) enhanced the survival of engrafted ADSC approximately 1.3-fold compared to MSC alone. This was associated with the idea that Rosuvastatin increased Akt, ERK phosphorylation, promoted the subsequent FoxO3a phosphorylation and nuclear export, and decreased the proapoptotic proteins in ADSCs [119].

\subsection{Another Optimization for MSC Therapy}

5.7.1. Time Point. Li and colleagues compared the time points for optimizing MSC efficacy. Among $1 \mathrm{~h}, 1$ week, and 2 weeks delivery after acute MI, time point of 1 week exhibited the most abundant MSC survival. Delivery at a later time point may lead to impeded cell retention, whereas cell administration too early may lead to poor engraftment due to the intensive inflammatory response in the acute stage [120]. According to an analysis of 7 randomized controlled trials with 660 patients with MI undergoing emergent percutaneous coronary intervention and receiving intracoronary BMSC transplantation, the effect of BMSC delivery at 4 to 7 days was superior to that within 24 hours [121].

5.7.2. Intactness. Adhesion is important for cell survival. Disruption of cell-ECM contact by trypsinization prior to cell transplantation may impair cell viability and facilitate apoptosis. Recently, improving MSC survival after transplantation with effective adhesion attracts much attention. MSCs were expanded on microcarrier beads in spin culture and directly transplanted, which avoided trypsinization and detachment of cell-ECM interaction, showing significantly less apoptosis than trypsinized control cells [122].

5.7.3. Extracorporeal Shock Wave. Genetically overexpression of SDF-1 in MSC can improve cell retention in ischemic myocardium [123]. Extracorporeal shock wave, similar to that used to treat nephrolithiasis, has been experimentally demonstrated to increase homing factor such as SDF-1 in target tissue [124]. Whether shock wave treatment can increase MSC retention requires further investigation. However, the phase I/II, double-blind, randomized, placebo-controlled trial CELLWAVE (NCT NCT00326989) conducted among patients reported that patients with chronic heart failure receiving shock wave treatment prior to intracoronary BMMNC infusion had a modest but significant improvement in LVEF compared to shock wave/placebo infusion [125]. Although the cell retention has not been evaluated in this trial, extracorporeal shock wave remains a strategy of interest in future.

\section{Discussion}

The poor viability of transplanted MSCs hampers their therapeutic efficacy for cardiac repair. A number of strategies have been conducted to augment the longevity of engraft cell in the hostile environment. We summarized the efficacy of promoting MSC survival with different strategies (Table 1, Figure 1). Myocardium injection has superior cell retention compared with other traditional routes such as catheter-based intracoronary infusion. MSCs seeded biocompatible materials scaffold delivered by injection or suturing to the epicardium hold promising potential. Biomaterials such as hydrogel can prevent the first wave loss of transplanted MSC due to the myocardium contraction. Preconditioning and genetic modification of MSCs can enhance the resistance of MSCs against hypoxia, oxidation, and inflammation. MSC transplantation together with CS/PC or Treg cells showed enhanced cell engraftment. Statin improves MSC survival after transplantation based on its multipotent function. A limitation of this review is that the efficacies of approaches improving cell retention are difficult to be compared with each other. This is 

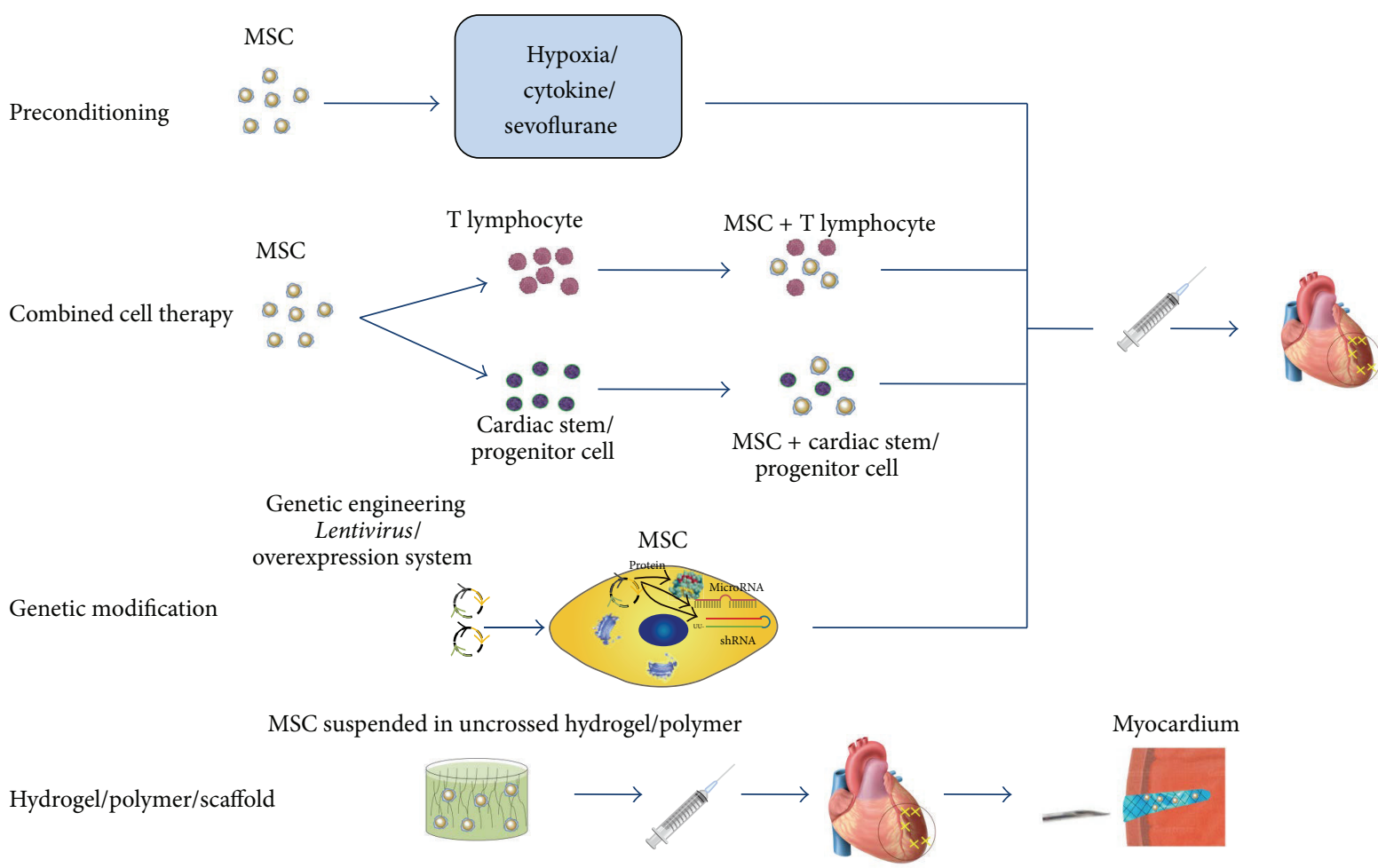

MSC seeded on biocompatible patch
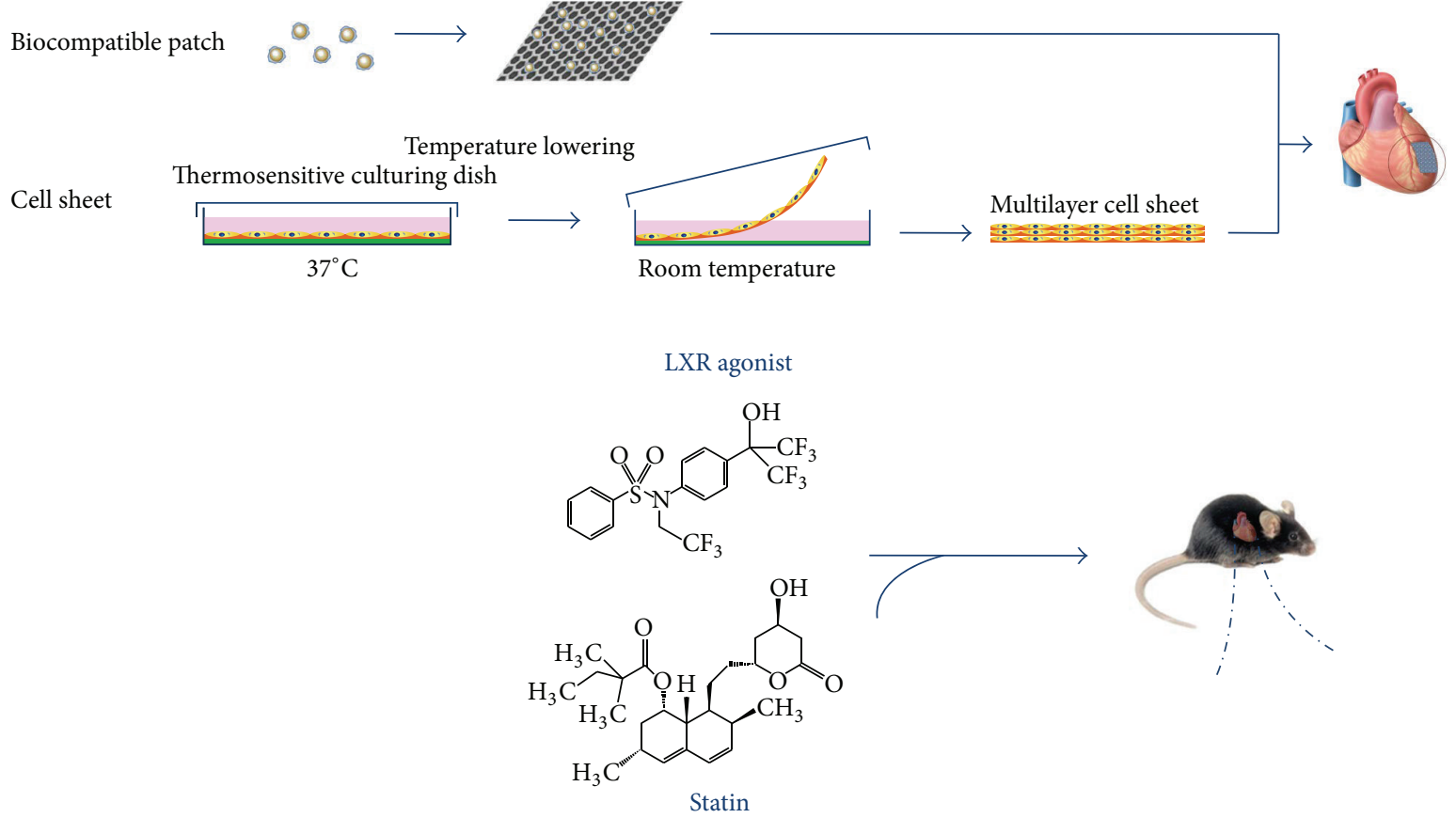

Medicine/compound delivery
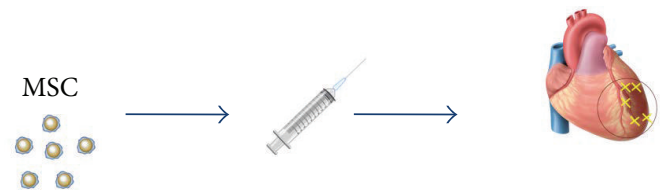

FIGURE 1: Schematic cartoon to illustrate the strategies to improve survival of MSC in ischemic myocardium. MSC can be either pretreated by hypoxia/cytokine or genetically modified before delivery to myocardium. Hydrogel/polymer with suspended MSC forms a semigrid scaffold when injected into the myocardium, which improves cell retention. MSC can be also seeded on biocompatible patch or form cell layer by culturing in thermosensitive dish; both of them can be deposited or sutured onto the epicardium of the infarcted area. Combined with another cell type (CSC, Treg cell) or medicine/compound (statin), they improve the survival of MSC. 


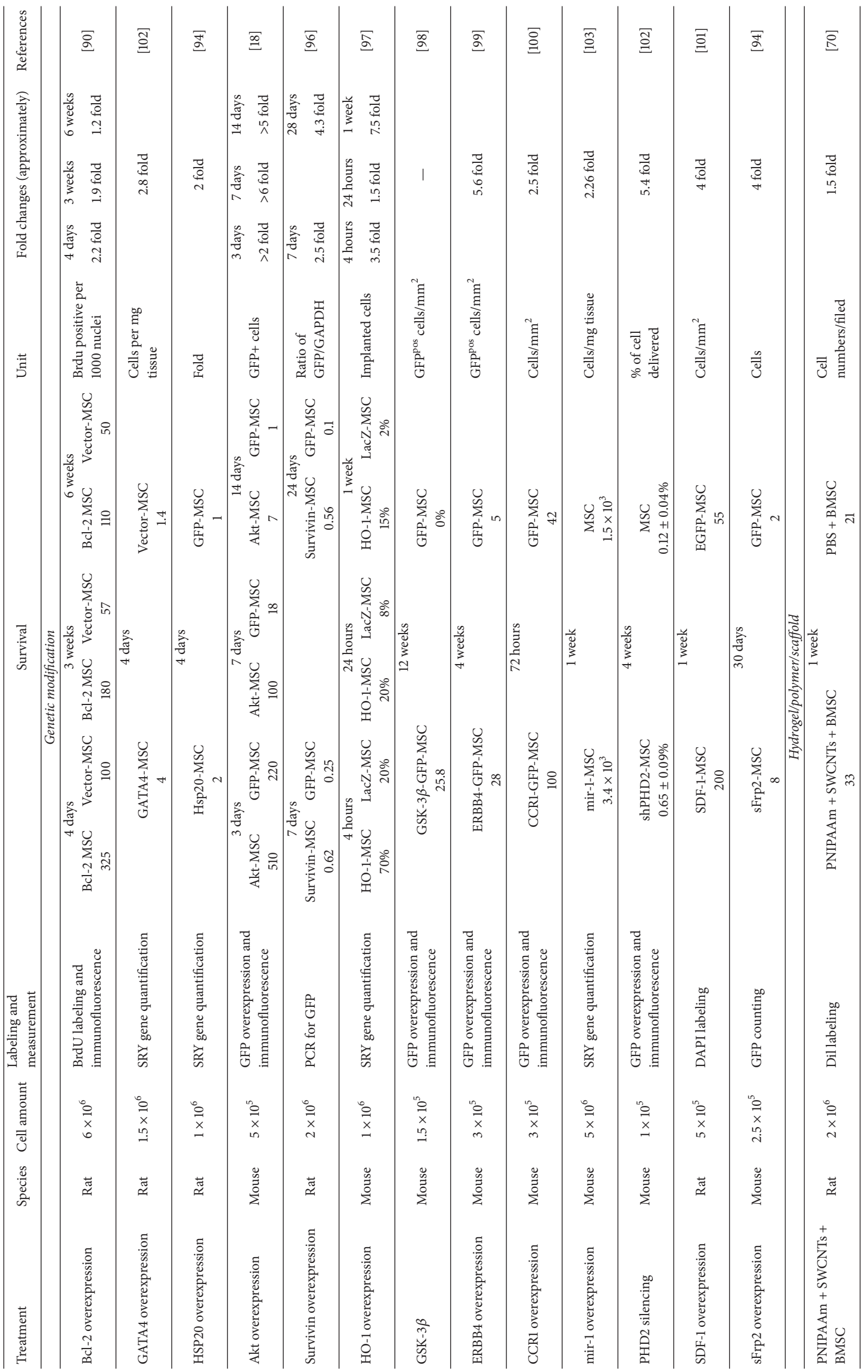




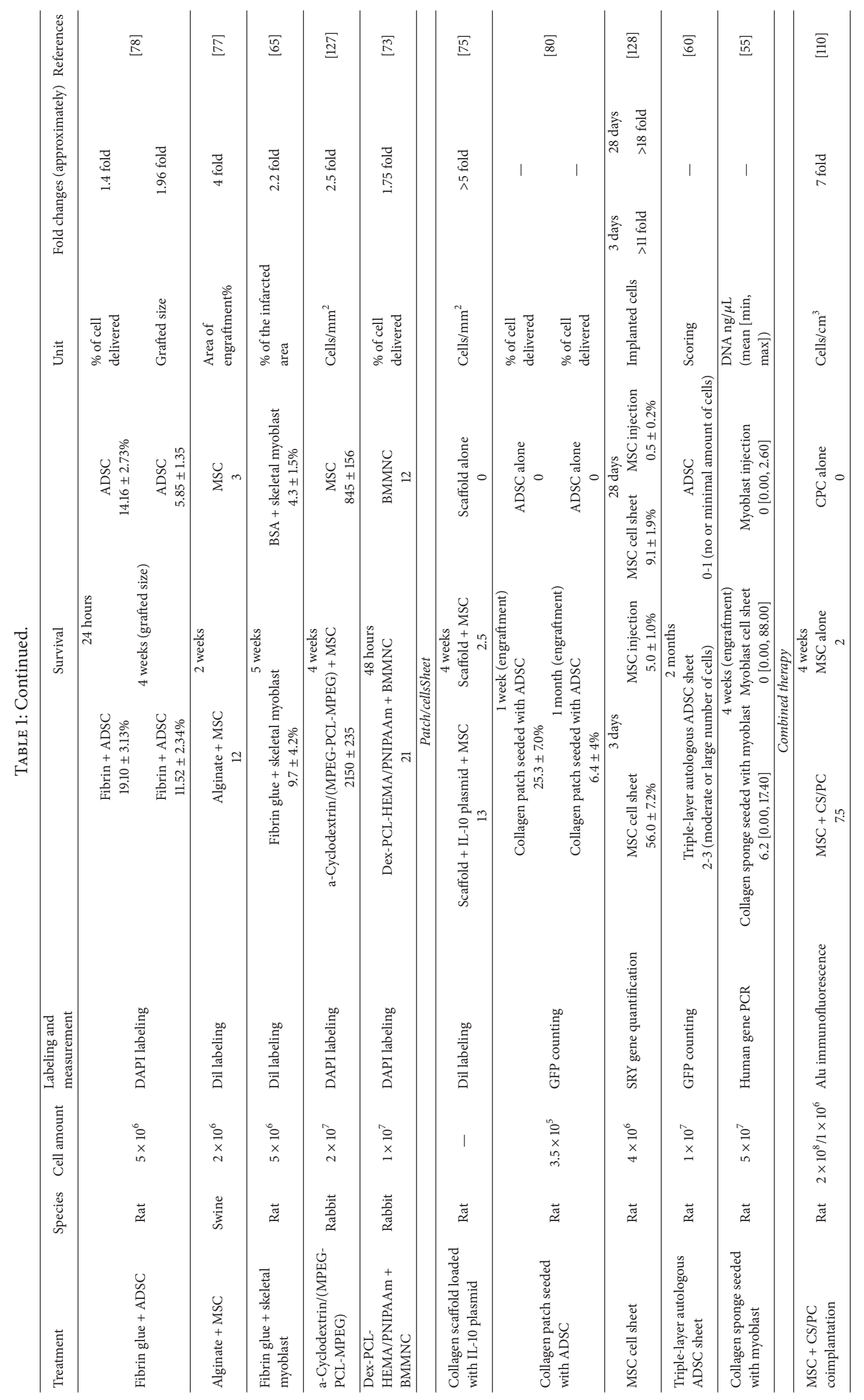




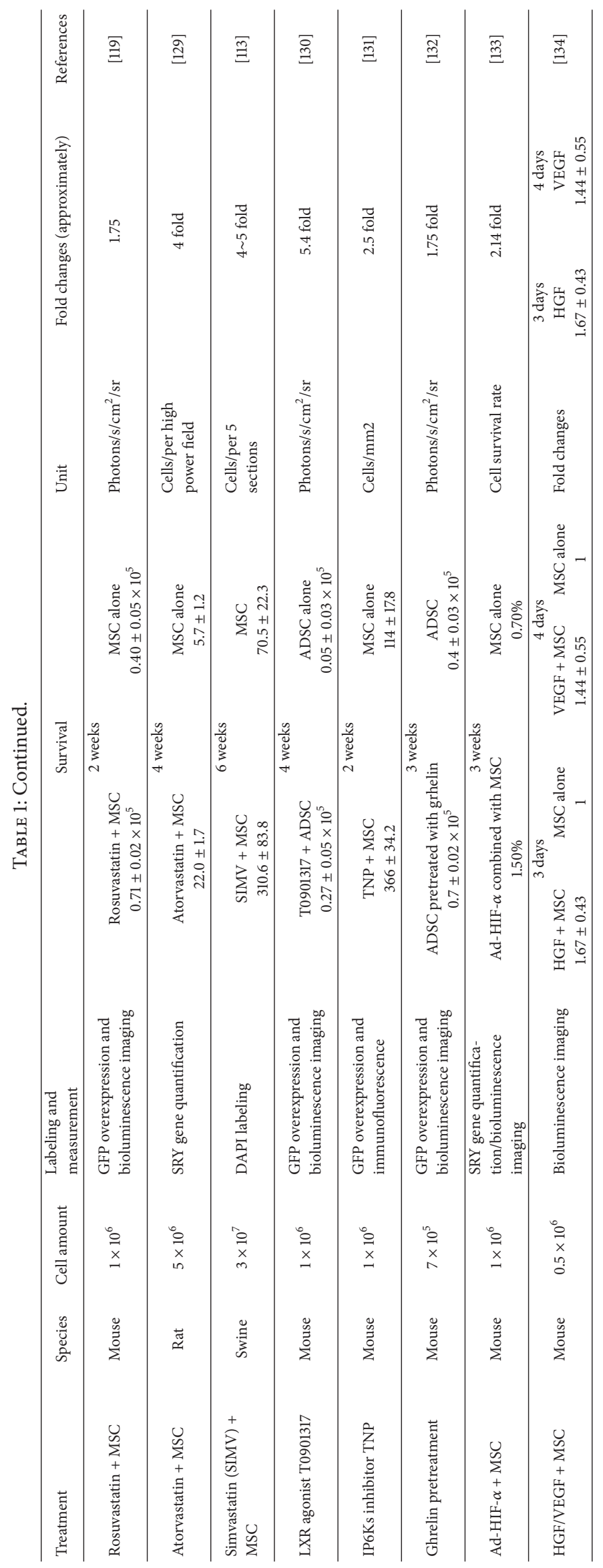


partially due to the measurements of cell retention in different studies.

As paracrine effects are nowadays considered as predominant therapeutic effect of MSCs [126], there is an attempt to apply functional fraction of conditioned medium (or its components such as exosome) of cultured MSCs instead of direct cell delivery to treat heart disease [3335]. However, some effects, including mitochondria transfer effect between MSC and cardiomyocytes [38], cannot be mimicked by paracrine factors alone. Further, the strategies acquired from MSC studies to promote cell survival have broader significance. Some stem cell types such as embryonic stem cell and inducible pluripotent stem cell (iPSC) have indisputable capacity to generate new cardiomyocytes, which are conducted in preclinical studies. The optimized methods for MSC transplantation can be tested in iPSC-derived cell treatment in ischemic myocardium, leading to greater efficacy for cardiac regeneration [127-134].

\section{Conflict of Interests}

The authors declare that there is no conflict of interests regarding the publication of this paper.

\section{References}

[1] S. J. Jansen Of Lorkeers, J. E. C. Eding, H. M. Vesterinen et al., "Similar effect of autologous and allogeneic cell therapy for ischemic heart disease: systematic review and meta-analysis of large animal studies," Circulation Research, vol. 116, no. 1, pp. 8086, 2015.

[2] N. Kawaguchi and T. Nakanishi, "Cardiomyocyte regeneration," Cells, vol. 2, no. 1, pp. 67-82, 2013.

[3] M. R. Rosen, R. J. Myerburg, D. P. Francis, G. D. Cole, and E. Marbán, "Translating stem cell research to cardiac disease therapies: pitfalls and prospects for improvement," Journal of the American College of Cardiology, vol. 64, no. 9, pp. 922-937, 2014.

[4] I.-K. Ko and B.-S. Kim, "Mesenchymal stem cells for treatment of myocardial infarction," International Journal of Stem Cells, vol. 1, no. 1, pp. 49-54, 2008.

[5] A. Farini, C. Sitzia, S. Erratico, M. Meregalli, and Y. Torrente, "Clinical applications of mesenchymal stem cells in chronic diseases," Stem Cells International, vol. 2014, Article ID 306573, 11 pages, 2014.

[6] A. J. Friedenstein, R. K. Chailakhjan, and K. S. Lalykina, "The development of fibroblast colonies in monolayer cultures of guinea-pig bone marrow and spleen cells," Cell and Tissue Kinetics, vol. 3, no. 4, pp. 393-403, 1970.

[7] P. A. Zuk, M. Zhu, H. Mizuno et al., "Multilineage cells from human adipose tissue: implications for cell-based therapies," Tissue Engineering, vol. 7, no. 2, pp. 211-228, 2001.

[8] C. De Bari, F. Dell'Accio, P. Tylzanowski, and F. P. Luyten, "Multipotent mesenchymal stem cells from adult human synovial membrane," Arthritis and Rheumatism, vol. 44, no. 8, pp. 19281942, 2001.

[9] F. Sabatini, L. Petecchia, M. Tavian, V. J. de Villeroché, G. A. Rossi, and D. Brouty-Boyé, "Human bronchial fibroblasts exhibit a mesenchymal stem cell phenotype and multilineage differentiating potentialities," Laboratory Investigation, vol. 85, no. 8, pp. 962-971, 2005.
[10] H. R. Jang, J. H. Park, G. Y. Kwon et al., "Effect of preemptive treatment with human umbilical cord blood-derived mesenchymal stem cells on the development of renal ischemiareperfusion injury in mice," American Journal of Physiology. Renal Physiology, vol. 307, no. 10, pp. F1149-F1161, 2014.

[11] N. J. Zvaifler, L. Marinova-Mutafchieva, G. Adams et al., "Mesenchymal precursor cells in the blood of normal individuals," Arthritis Research, vol. 2, no. 6, pp. 477-488, 2000.

[12] Y.-S. Huang, I.-H. Li, S.-H. Chueh et al., "Mesenchymal stem cells from rat olfactory bulbs can differentiate into cells with cardiomyocyte characteristics," Journal of Tissue Engineering and Regenerative Medicine, 2013.

[13] L. da Silva Meirelles, P. C. Chagastelles, and N. B. Nardi, "Mesenchymal stem cells reside in virtually all post-natal organs and tissues," Journal of Cell Science, vol. 119, no. 11, pp. 2204$2213,2006$.

[14] A. H. Piersma, K. G. M. Brockbank, R. E. Ploemacher, E. van Vliet, K. M. Brakel-van Peer, and P. J. Visser, "Characterization of fibroblastic stromal cells from murine bone marrow," Experimental Hematology, vol. 13, no. 4, pp. 237-243, 1985.

[15] E. Y. Plotnikov, T. G. Khryapenkova, A. K. Vasileva et al., "Cell-to-cell cross-talk between mesenchymal stem cells and cardiomyocytes in co-culture," Journal of Cellular and Molecular Medicine, vol. 12, no. 5, pp. 1622-1631, 2008.

[16] C. Toma, M. F. Pittenger, K. S. Cahill, B. J. Byrne, and P. D. Kessler, "Human mesenchymal stem cells differentiate to a cardiomyocyte phenotype in the adult murine heart," Circulation, vol. 105, no. 1, pp. 93-98, 2002.

[17] S. Fazel, L. Chen, R. D. Weisel et al., "Cell transplantation preserves cardiac function after infarction by infarct stabilization: augmentation by stem cell factor," The Journal of Thoracic and Cardiovascular Surgery, vol. 130, no. 5, pp. 1310.e1-1310.e10, 2005.

[18] N. Noiseux, M. Gnecchi, M. Lopez-Ilasaca et al., "Mesenchymal stem cells overexpressing Akt dramatically repair infarcted myocardium and improve cardiac function despite infrequent cellular fusion or differentiation," Molecular Therapy, vol. 14, no. 6, pp. 840-850, 2006.

[19] A. Keating, "Mesenchymal stromal cells: new directions," Cell Stem Cell, vol. 10, no. 6, pp. 709-716, 2012.

[20] M. Dominici, K. Le Blanc, I. Mueller et al., "Minimal criteria for defining multipotent mesenchymal stromal cells. The International Society for Cellular Therapy position statement," Cytotherapy, vol. 8, no. 4, pp. 315-317, 2006.

[21] C. Nombela-Arrieta, J. Ritz, and L. E. Silberstein, "The elusive nature and function of mesenchymal stem cells," Nature Reviews: Molecular Cell Biology, vol. 12, no. 2, pp. 126-131, 2011.

[22] R. A. Panepucci, J. L. C. Siufi, W. A. Silva Jr. et al., "Comparison of gene expression of umbilical cord vein and bone marrowderived mesenchymal stem cells," Stem Cells, vol. 22, no. 7, pp. 1263-1278, 2004.

[23] R. H. Lee, B. Kim, I. Choi et al., "Characterization and expression analysis of mesenchymal stem cells from human bone marrow and adipose tissue," Cellular Physiology and Biochemistry, vol. 14, no. 4-6, pp. 311-324, 2004.

[24] S. Tomita, R.-K. Li, R. D. Weisel et al., "Autologous transplantation of bone marrow cells improves damaged heart function," Circulation, vol. 100, no. 19, pp. II247-II256, 1999.

[25] K. E. Hatzistergos, H. Quevedo, B. N. Oskouei et al., "Bone marrow mesenchymal stem cells stimulate cardiac stem cell 
proliferation and differentiation," Circulation Research, vol. 107, no. 7, pp. 913-922, 2010.

[26] S. Wakitani, T. Saito, and A. I. Caplan, "Myogenic cells derived from rat bone marrow mesenchymal stem cells exposed to 5azacytidine," Muscle \& Nerve, vol. 18, no. 12, pp. 1417-1426, 1995.

[27] S. Fazel, L. Chen, R. D. Weisel et al., "Cell transplantation preserves cardiac function after infarction by infarct stabilization: augmentation by stem cell factor," Journal of Thoracic and Cardiovascular Surgery, vol. 130, no. 5, pp. 1310.e1-1310.e10, 2005.

[28] H. Reinecke, E. Minami, W.-Z. Zhu, and M. A. Laflamme, "Cardiogenic differentiation and transdifferentiation of progenitor cells," Circulation Research, vol. 103, no. 10, pp. 1058-1071, 2008.

[29] M. Z. Ratajczak, M. Kucia, T. Jadczyk et al., "Pivotal role of paracrine effects in stem cell therapies in regenerative medicine: can we translate stem cell-secreted paracrine factors and microvesicles into better therapeutic strategies," Leukemia, vol. 26, no. 6, pp. 1166-1173, 2012.

[30] R. C. Scott, J. M. Rosano, Z. Ivanov et al., "Targeting VEGFencapsulated immunoliposomes to MI heart improves vascularity and cardiac function," The FASEB Journal, vol. 23, no. 10, pp. 3361-3367, 2009.

[31] J. A. I. Virag, M. L. Rolle, J. Reece, S. Hardouin, E. O. Feigl, and C. E. Murry, "Fibroblast growth factor-2 regulates myocardial infarct repair: effects on cell proliferation, scar contraction, and ventricular function," The American Journal of Pathology, vol. 171, no. 5, pp. 1431-1440, 2007.

[32] E. Ruvinov, J. Leor, and S. Cohen, “The promotion of myocardial repair by the sequential delivery of IGF-1 and HGF from an injectable alginate biomaterial in a model of acute myocardial infarction," Biomaterials, vol. 32, no. 2, pp. 565-578, 2011.

[33] L. Huang, W. Ma, Y. Ma, D. Feng, H. Chen, and B. Cai, "Exosomes in mesenchymal stem cells, a new therapeutic strategy for cardiovascular diseases?" International Journal of Biological Sciences, vol. 11, no. 2, pp. 238-245, 2015.

[34] Y. Feng, W. Huang, M. Wani, X. Yu, and M. Ashraf, "Ischemic preconditioning potentiates the protective effect of stem cells through secretion of exosomes by targeting Mecp2 via miR-22," PLoS ONE, vol. 9, no. 2, Article ID e88685, 2014.

[35] B. Yu, M. Gong, Y. Wang et al., "Cardiomyocyte protection by gata- 4 gene engineered mesenchymal stem cells is partially mediated by translocation of mir-221 in microvesicles," PLOS ONE, vol. 8, no. 8, Article ID e73304, 2013.

[36] F. Arslan, R. C. Lai, M. B. Smeets et al., "Mesenchymal stem cell-derived exosomes increase ATP levels, decrease oxidative stress and activate PI3K/Akt pathway to enhance myocardial viability and prevent adverse remodeling after myocardial ischemia/reperfusion injury," Stem Cell Research, vol. 10, no. 3, pp. 301-312, 2013.

[37] J. L. Spees, S. D. Olson, M. J. Whitney, and D. J. Prockop, "Mitochondrial transfer between cells can rescue aerobic respiration," Proceedings of the National Academy of Sciences of the United States of America, vol. 103, no. 5, pp. 1283-1288, 2006.

[38] A. Acquistapace, T. Bru, P.-F. Lesault et al., "Human mesenchymal stem cells reprogram adult cardiomyocytes toward a progenitor-like state through partial cell fusion and mitochondria transfer," Stem Cells, vol. 29, no. 5, pp. 812-824, 2011.

[39] B. E. Strauer, M. Brehm, T. Zeus et al., "Intracoronary, human autologous stem cell transplantation for myocardial regeneration following myocardial infarction," Deutsche Medizinische Wochenschrift, vol. 126, pp. 932-938, 2001.
[40] K. C. Wollert, G. P. Meyer, J. Lotz et al., "Intracoronary autologous bone-marrow cell transfer after myocardial infarction: the boost randomised controlled clinical trial," The Lancet, vol. 364, no. 9429, pp. 141-148, 2004.

[41] K. S. Telukuntla, V. Y. Suncion, I. H. Schulman, and J. M. Hare, "The advancing field of cell-based therapy: insights and lessons from clinical trials," Journal of the American Heart Association, vol. 2, no. 5, Article ID e000338, 2013.

[42] J. M. Hare, J. E. Fishman, G. Gerstenblith et al., "Comparison of allogeneic vs autologous bone marrow-derived mesenchymal stem cells delivered by transendocardial injection in patients with ischemic cardiomyopathy: the POSEIDON randomized trial," The Journal of the American Medical Association, vol. 308, no. 22, pp. 2369-2379, 2012.

[43] J. Bartunek, A. Behfar, D. Dolatabadi et al., "Cardiopoietic stem cell therapy in heart failure: the c-cure (cardiopoietic stem cell therapy in heart failure) multicenter randomized trial with lineage-specified biologics," Journal of the American College of Cardiology, vol. 61, no. 23, pp. 2329-2338, 2013.

[44] A. W. Heldman, D. L. DiFede, J. E. Fishman et al., “Transendocardial mesenchymal stem cells and mononuclear bone marrow cells for ischemic cardiomyopathy: the TAC-HFT randomized trial," Journal of the American Medical Association, vol. 311, no. 1, pp. 62-73, 2014.

[45] A. B. Mathiasen, A. A. Qayyum, E. Jorgensen et al., "Bone marrow-derived mesenchymal stromal cell treatment in patients with severe ischaemic heart failure: a randomized placebo-controlled trial (MSC-HF trial)," European Heart Journal, 2015.

[46] S.-L. Chen, W.-W. Fang, F. Ye et al., "Effect on left ventricular function of intracoronary transplantation of autologous bone marrow mesenchymal stem cell in patients with acute myocardial infarction," The American Journal of Cardiology, vol. 94, no. 1, pp. 92-95, 2004.

[47] A. E. Ting and W. Sherman, "Allogeneic stem cell transplantation for ischemic myocardial dysfunction," Current Opinion in Organ Transplantation, vol. 17, no. 6, pp. 675-680, 2012.

[48] E. Martin-Rendon, S. J. Brunskill, C. J. Hyde, S. J. Stanworth, A. Mathur, and S. M. Watt, "Autologous bone marrow stem cells to treat acute myocardial infarction: a systematic review," European Heart Journal, vol. 29, no. 15, pp. 1807-1818, 2008.

[49] K. Lunde, S. Solheim, S. Aakhus et al., "Intracoronary injection of mononuclear bone marrow cells in acute myocardial infarction," The New England Journal of Medicine, vol. 355, no. 12, pp. 1199-1209, 2006.

[50] M. Gyöngyösi, J. Blanco, T. Marian et al., "Serial noninvasive in vivo positron emission tomographic tracking of percutaneously intramyocardially injected autologous porcine mesenchymal stem cells modified for transgene reporter gene expression," Circulation: Cardiovascular Imaging, vol. 1, no. 2, pp. 94-103, 2008.

[51] L. M. McGinley, J. McMahon, A. Stocca et al., "Mesenchymal stem cell survival in the infarcted heart is enhanced by lentivirus vector-mediated heat shock protein 27 expression," Human Gene Therapy, vol. 24, no. 10, pp. 840-851, 2013.

[52] M. Hofmann, K. C. Wollert, G. P. Meyer et al., "Monitoring of bone marrow cell homing into the infarcted human myocardium," Circulation, vol. 111, no. 17, pp. 2198-2202, 2005.

[53] A. Facciabene, X. Peng, I. S. Hagemann et al., “Tumour hypoxia promotes tolerance and angiogenesis via CCL28 and T ${ }_{\text {reg }}$ cells," Nature, vol. 475, no. 7355, pp. 226-230, 2011. 
[54] V. Schächinger, A. Aicher, N. Döbert et al., "Pilot trial on determinants of progenitor cell recruitment to the infarcted human myocardium," Circulation, vol. 118, no. 14, pp. 1425-1432, 2008.

[55] H. Hamdi, A. Furuta, V. Bellamy et al., "Cell delivery: intramyocardial injections or epicardial deposition? A head-to-head comparison," Annals of Thoracic Surgery, vol. 87, no. 4, pp. 11961203, 2009.

[56] A. Elsässer, K. Suzuki, S. Lorenz-Meyer, C. Bode, and J. Schaper, "The role of apoptosis in myocardial ischemia: a critical appraisal," Basic Research in Cardiology, vol. 96, no. 3, pp. 219226, 2001.

[57] C. A. Thompson, B. A. Nasseri, J. Makower et al., "Percutaneous transvenous cellular cardiomyoplasty: a novel nonsurgical approach for myocardial cell transplantation," Journal of the American College of Cardiology, vol. 41, no. 11, pp. 1964-1971, 2003.

[58] D. Hou, E. A.-S. Youssef, T. J. Brinton et al., "Radiolabeled cell distribution after intramyocardial, intracoronary, and interstitial retrograde coronary venous delivery: implications for current clinical trials," Circulation, vol. 112, no. 9, pp. I150-I156, 2005.

[59] S. Fukushima, A. Varela-Carver, S. R. Coppen et al., "Direct intramyocardial but not intracoronary injection of bone marrow cells induces ventricular arrhythmias in a rat chronic ischemic heart failure model," Circulation, vol. 115, no. 17, pp. 2254-2261, 2007.

[60] H. Hamdi, V. Planat-Benard, A. Bel et al., "Epicardial adipose stem cell sheets results in greater post-infarction survival than intramyocardial injections," Cardiovascular Research, vol. 91, no. 3, pp. 483-491, 2011.

[61] J. Leor, S. Aboulafia-Etzion, A. Dar et al., "Bioengineered cardiac grafts: a new approach to repair the infarcted myocardium?" Circulation, vol. 102, no. 19, pp. III56-III61, 2000.

[62] W. H. Zimmermann, C. Fink, D. Kralisch, U. Remmers, J. Weil, and T. Eschenhagen, "Three-dimensional engineered heart tissue from neonatal rat cardiac myocytes," Biotechnology and Bioengineering, vol. 68, no. 1, pp. 106-114, 2000.

[63] W.-H. Zimmermann, I. Melnychenko, and T. Eschenhagen, "Engineered heart tissue for regeneration of diseased hearts," Biomaterials, vol. 25, no. 9, pp. 1639-1647, 2004.

[64] J. Jin, S. I. Jeong, Y. M. Shin et al., “Transplantation of mesenchymal stem cells within a poly(lactide-co-epsilon-caprolactone) scaffold improves cardiac function in a rat myocardial infarction model," European Journal of Heart Failure, vol. 11, no. 2, pp. 147-153, 2009.

[65] K. L. Christman, A. J. Vardanian, Q. Fang, R. E. Sievers, H. H. Fok, and R. J. Lee, "Injectable fibrin scaffold improves cell transplant survival, reduces infarct expansion, and induces neovasculature formation in ischemic myocardium," Journal of the American College of Cardiology, vol. 44, no. 3, pp. 654-660, 2004.

[66] P. Maureira, P.-Y. Marie, F. Yu et al., "Repairing chronic myocardial infarction with autologous mesenchymal stem cells engineered tissue in rat promotes angiogenesis and limits ventricular remodeling," Journal of Biomedical Science, vol. 19, no. 1, article 93, 2012.

[67] J. Leor, S. Tuvia, V. Guetta et al., "Intracoronary injection of in situ forming alginate hydrogel reverses left ventricular remodeling after myocardial infarction in swine," Journal of the
American College of Cardiology, vol. 54, no. 11, pp. 1014-1023, 2009.

[68] P. Sreejit and R. S. Verma, "Cardiogel supports adhesion, proliferation and differentiation of stem cells with increased oxidative stress protection," European Cells \& Materials, vol. 21, pp. 107-121, 2011.

[69] X. Bourges, P. Weiss, G. Daculsi, and G. Legeay, "Synthesis and general properties of silated-hydroxypropyl methylcellulose in prospect of biomedical use," Advances in Colloid and Interface Science, vol. 99, no. 3, pp. 215-228, 2002.

[70] X. Li, J. Zhou, Z. Liu et al., "A PNIPAAm-based thermosensitive hydrogel containing SWCNTs for stem cell transplantation in myocardial repair," Biomaterials, vol. 35 , no. 22, pp. 5679-5688, 2014.

[71] C. Ceccaldi, R. Bushkalova, C. Alfarano et al., "Evaluation of polyelectrolyte complex-based scaffolds for mesenchymal stem cell therapy in cardiac ischemia treatment," Acta Biomaterialia, vol. 10, no. 2, pp. 901-911, 2014.

[72] R. Ravichandran, J. R. Venugopal, S. Sundarrajan, S. Mukherjee, and S. Ramakrishna, "Cardiogenic differentiation of mesenchymal stem cells on elastomeric poly (glycerol sebacate)/collagen core/shell fibers," World Journal of Cardiology, vol. 5, no. 3, pp. 28-41, 2013.

[73] X.-Y. Li, T. Wang, X.-J. Jiang et al., "Injectable hydrogel helps bone marrow-derived mononuclear cells restore infarcted myocardium," Cardiology, vol. 115, no. 3, pp. 194-199, 2010.

[74] X. Bourges, P. Weiss, A. Coudreuse, G. Daculsi, and G. Legeay, "General properties of silated hydroxyethylcellulose for potential biomedical applications," Biopolymers, vol. 63, no. 4, pp. 232-238, 2002.

[75] C. A. Holladay, A. M. Duffy, X. Chen, M. V. Sefton, T. D. O'Brien, and A. S. Pandit, "Recovery of cardiac function mediated by MSC and interleukin-10 plasmid functionalised scaffold," Biomaterials, vol. 33, no. 5, pp. 1303-1314, 2012.

[76] E. Mathieu, G. Lamirault, C. Toquet et al., "Intramyocardial delivery of mesenchymal stem cell-seeded hydrogel preserves cardiac function and attenuates ventricular remodeling after myocardial infarction," PLoS ONE, vol. 7, no. 12, Article ID e51991, 2012.

[77] N. C. Panda, S. T. Zuckerman, O. O. Mesubi et al., "Improved conduction and increased cell retention in healed MI using mesenchymal stem cells suspended in alginate hydrogel," Journal of Interventional Cardiac Electrophysiology, vol. 41, no. 2, pp. 117-127, 2014.

[78] X. Zhang, H. Wang, X. Ma et al., "Preservation of the cardiac function in infarcted rat hearts by the transplantation of adipose-derived stem cells with injectable fibrin scaffolds," Experimental Biology and Medicine, vol. 235, no. 12, pp. 1505$1515,2010$.

[79] N. Frey, A. Linke, T. Suselbeck et al., "Intracoronary delivery of injectable bioabsorbable scaffold (ik-5001) to treat left ventricular remodeling after st-elevation myocardial infarction: a firstin-man study," Circulation: Cardiovascular Interventions, vol. 7, no. 6, pp. 806-812, 2014.

[80] M. Araña, J. J. Gavira, E. Peña et al., "Epicardial delivery of collagen patches with adipose-derived stem cells in rat and minipig models of chronic myocardial infarction," Biomaterials, vol. 35, no. 1, pp. 143-151, 2014.

[81] J. H. Li, N. Zhang, and J. A. Wangi, "Improved anti-apoptotic and anti-remodeling potency of bone marrow mesenchymal 
stem cells by anoxic pre-conditioning in diabetic cardiomyopathy," Journal of Endocrinological Investigation, vol. 31, no. 2, pp. 103-110, 2008.

[82] X. Hu, S. P. Yu, J. L. Fraser et al., “Transplantation of hypoxiapreconditioned mesenchymal stem cells improves infarcted heart function via enhanced survival of implanted cells and angiogenesis," Journal of Thoracic and Cardiovascular Surgery, vol. 135, no. 4, pp. 799-808, 2008.

[83] L. Wang, X. Hu, W. Zhu et al., "Increased leptin by hypoxicpreconditioning promotes autophagy of mesenchymal stem cells and protects them from apoptosis," Science China Life Sciences, vol. 57, no. 2, pp. 171-180, 2014.

[84] U. Saini, R. J. Gumina, B. Wolfe, M. L. Kuppusamy, P. Kuppusamy, and K. D. Boudoulas, "Preconditioning mesenchymal stem cells with caspase inhibition and hyperoxia prior to hypoxia exposure increases cell proliferation," Journal of Cellular Biochemistry, vol. 114, no. 11, pp. 2612-2623, 2013.

[85] F. Figeac, P.-F. Lesault, O. Le Coz et al., "Nanotubular crosstalk with distressed cardiomyocytes stimulates the paracrine repair function of mesenchymal stem cells," Stem Cells, vol. 32, no. 1, pp. 216-230, 2014.

[86] J. L. Herrmann, Y. Wang, A. M. Abarbanell, B. R. Weil, J. Tan, and D. R. Meldrum, "Preconditioning mesenchymal stem cells with transforming growth factor-alpha improves mesenchymal stem cell-mediated cardioprotection," Shock, vol. 33, no. 1, pp. 24-30, 2010.

[87] B. Xu, Y. Luo, Y. Liu, B. Y. Li, and Y. Wang, "Platelet-derived growth factor-BB enhances MSC-mediated cardioprotection via suppression of miR-320 expression," The American Journal of Physiology-Heart and Circulatory Physiology, vol. 308, no. 9, pp. H980-H989, 2015.

[88] S. Filip, J. Mokry, J. Horacek, and D. English, "Stem cells and the phenomena of plasticity and diversity: a limiting property of carcinogenesis," Stem Cells and Development, vol. 17, no. 6, pp. 1031-1038, 2008.

[89] Q. Mao, C. Lin, J. Gao et al., "Mesenchymal stem cells overexpressing integrin-linked kinase attenuate left ventricular remodeling and improve cardiac function after myocardial infarction," Molecular and Cellular Biochemistry, vol. 397, no. 12, pp. 203-214, 2014.

[90] W. Li, N. Ma, L.-L. Ong et al., "Bcl-2 engineered MSCs inhibited apoptosis and improved heart function," Stem Cells, vol. 25, no. 8, pp. 2118-2127, 2007.

[91] S. Y. Lim, Y. S. Kim, Y. Ahn et al., “The effects of mesenchymal stem cells transduced with Akt in a porcine myocardial infarction model," Cardiovascular Research, vol. 70, no. 3, pp. 530-542, 2006.

[92] M. Gnecchi, H. He, N. Noiseux et al., "Evidence supporting paracrine hypothesis for Akt-modified mesenchymal stem cellmediated cardiac protection and functional improvement," The FASEB Journal, vol. 20, no. 6, pp. 661-669, 2006.

[93] S. Jiang, H. K. Haider, N. M. Idris, A. Salim, and M. Ashraf, "Supportive interaction between cell survival signaling and angiocompetent factors enhances donor cell survival and promotes angiomyogenesis for cardiac repair," Circulation Research, vol. 99, no. 7, pp. 776-784, 2006.

[94] X. Wang, T. Zhao, W. Huang et al., "Hsp20-engineered mesenchymal stem cells are resistant to oxidative stress via enhanced activation of Akt and increased secretion of growth factors," Stem Cells, vol. 27, no. 12, pp. 3021-3031, 2009.
[95] M. Mirotsou, Z. Zhang, A. Deb et al., "Secreted frizzled related protein 2 (Sfrp2) is the key Akt-mesenchymal stem cell-released paracrine factor mediating myocardial survival and repair," Proceedings of the National Academy of Sciences of the United States of America, vol. 104, no. 5, pp. 1643-1648, 2007.

[96] L. Fan, C. Lin, S. Zhuo et al., "Transplantation with survivinengineered mesenchymal stem cells results in better prognosis in a rat model of myocardial infarction," European Journal of Heart Failure, vol. 11, no. 11, pp. 1023-1030, 2009.

[97] Y. L. Tang, Y. Tang, Y. C. Zhang, K. Qian, L. Shen, and M. I. Phillips, "Improved graft mesenchymal stem cell survival in ischemic heart with a hypoxia-regulated heme oxygenase-1 vector," Journal of the American College of Cardiology, vol. 46, no. 7, pp. 1339-1350, 2005.

[98] J. Cho, P. Zhai, Y. Maejima, and J. Sadoshima, "Myocardial injection with GSK-3 $\beta$-overexpressing bone marrow-derived mesenchymal stem cells attenuates cardiac dysfunction after myocardial infarction," Circulation Research, vol. 108, no. 4, pp. 478-489, 2011.

[99] S. H. Ranganath, O. Levy, M. S. Inamdar, and J. M. Karp, "Harnessing the mesenchymal stem cell secretome for the treatment of cardiovascular disease," Cell Stem Cell, vol. 10, no. 3, pp. 244-258, 2012.

[100] J. Huang, Z. Zhang, J. Guo et al., "Genetic modification of mesenchymal stem cells overexpressing CCR1 increases cell viability, migration, engraftment, and capillary density in the injured myocardium," Circulation Research, vol. 106, no. 11, pp. 1753-1762, 2010.

[101] J. Tang, J. Wang, L. Guo et al., "Mesenchymal stem cells modified with stromal cell-derived factor $1 \alpha$ improve cardiac remodeling via paracrine activation of hepatocyte growth factor in a rat model of myocardial infarction," Molecules and Cells, vol. 29, no. 1, pp. 9-19, 2010.

[102] W. E. Wang, D. Yang, L. Li et al., "Prolyl hydroxylase domain protein 2 silencing enhances the survival and paracrine function of transplanted adipose-derived stem cells in infarcted myocardium," Circulation Research, vol. 113, no. 3, pp. 288-300, 2013.

[103] H. Li, S. Zuo, Z. He et al., "Paracrine factors released by GATA4 overexpressed mesenchymal stem cells increase angiogenesis and cell survival," The American Journal of Physiology-Heart and Circulatory Physiology, vol. 299, no. 6, pp. H1772-H1781, 2010.

[104] F. Huang, M.-L. Li, Z.-F. Fang et al., "Overexpression of MicroRNA-1 improves the efficacy of mesenchymal stem cell transplantation after myocardial infarction," Cardiology, vol. 125, no. 1, pp. 18-30, 2013.

[105] J. Xu, Z. Huang, L. Lin et al., "miR-210 over-expression enhances mesenchymal stem cell survival in an oxidative stress environment through antioxidation and c-Met pathway activation," Science China. Life Sciences, vol. 57, no. 10, pp. 989-997, 2014.

[106] A. P. Beltrami, L. Barlucchi, D. Torella et al., "Adult cardiac stem cells are multipotent and support myocardial regeneration," Cell, vol. 114, no. 6, pp. 763-776, 2003.

[107] R. Bolli, A. R. Chugh, D. D’Amario et al., "Cardiac stem cells in patients with ischaemic cardiomyopathy (SCIPIO): initial results of a randomised phase 1 trial," The Lancet, vol. 378, no. 9806, pp. 1847-1857, 2011.

[108] R. Mazhari and J. M. Hare, "Mechanisms of action of mesenchymal stem cells in cardiac repair: potential influences on the 
cardiac stem cell niche," Nature Clinical Practice Cardiovascular Medicine, vol. 4, supplement 1, pp. S21-S26, 2007.

[109] B. N. Oskouei, G. Lamirault, C. Joseph et al., "Increased potency of cardiac stem cells compared with bone marrow mesenchymal stem cells in cardiac repair," Stem Cells Translational Medicine, vol. 1, no. 2, pp. 116-124, 2012.

[110] A. R. Williams, K. E. Hatzistergos, B. Addicott et al., "Enhanced effect of combining human cardiac stem cells and bone marrow mesenchymal stem cells to reduce infarct size and to restore cardiac function after myocardial infarction," Circulation, vol. 127, no. 2, pp. 213-223, 2013.

[111] A. Facciabene, G. T. Motz, and G. Coukos, "T-regulatory cells: key players in tumor immune escape and angiogenesis," Cancer Research, vol. 72, no. 9, pp. 2162-2171, 2012.

[112] Y. Zhou, A. K. Singh, R. F. Hoyt Jr. et al., "Regulatory T cells enhance mesenchymal stem cell survival and proliferation following autologous cotransplantation in ischemic myocardium," The Journal of Thoracic and Cardiovascular Surgery, vol. 148, no. 3, pp. 1131-1137, 2014.

[113] Y.-J. Yang, J.-L. Zhao, S.-J. You et al., "Post-infarction treatment with simvastatin reduces myocardial no-reflow by opening of the KATP channel," European Journal of Heart Failure, vol. 9, no. 1, pp. 30-36, 2007.

[114] C. P. Sparrow, C. A. Burton, M. Hernandez et al., "Simvastatin has anti-inflammatory and antiatherosclerotic activities independent of plasma cholesterol lowering," Arteriosclerosis, Thrombosis, and Vascular Biology, vol. 21, no. 1, pp. 115-121, 2001.

[115] B. Assmus, C. Urbich, A. Aicher et al., "HMG-CoA reductase inhibitors reduce senescence and increase proliferation of endothelial progenitor cells via regulation of cell cycle regulatory genes," Circulation Research, vol. 92, no. 9, pp. 10491055, 2003.

[116] B. Kwak, F. Mulhaupt, S. Myit, and F. Mach, "Statins as a newly recognized type of immunomodulator," Nature Medicine, vol. 6, no. 12, pp. 1399-1402, 2000.

[117] J.-D. Luo, F. Xie, W.-W. Zhang, X.-D. Ma, J.-X. Guan, and X. Chen, "Simvastatin inhibits noradrenaline-induced hypertrophy of cultured neonatal rat cardiomyocytes," British Journal of Pharmacology, vol. 132, no. 1, pp. 159-164, 2001.

[118] Y.-J. Yang, H.-Y. Qian, J. Huang et al., “Combined therapy with simvastatin and bone marrow-derived mesenchymal stem cells increases benefits in infarcted swine hearts," Arteriosclerosis, Thrombosis, and Vascular Biology, vol. 29, no. 12, pp. 2076-2082, 2009.

[119] Z. Zhang, S. Li, M. Cui et al., "Rosuvastatin enhances the therapeutic efficacy of adipose-derived mesenchymal stem cells for myocardial infarction via PI3K/Akt and MEK/ERK pathways," Basic Research in Cardiology, vol. 108, no. 2, article 333, 2013.

[120] X. Hu, J. Wang, J. Chen et al., "Optimal temporal delivery of bone marrow mesenchymal stem cells in rats with myocardial infarction," European Journal of Cardio-Thoracic Surgery, vol. 31, no. 3, pp. 438-443, 2007.

[121] S. Zhang, A. Sun, D. Xu et al., "Impact of timing on efficacy and safety of intracoronary autologous bone marrow stem cells transplantation in acute myocardial infarction: a pooled subgroup analysis of randomized controlled trials," Clinical Cardiology, vol. 32, no. 8, pp. 458-466, 2009.

[122] Y. Yang, F. M. V. Rossi, and E. E. Putnins, "Ex vivo expansion of rat bone marrow mesenchymal stromal cells on microcarrier beads in spin culture," Biomaterials, vol. 28, no. 20, pp. 31103120, 2007.
[123] R. Sarugaser, L. Hanoun, A. Keating, W. L. Stanford, and J. E. Davies, "Human mesenchymal stem cells self-renew and differentiate according to a deterministic hierarchy," PLOS ONE, vol. 4, no. 8, Article ID e6498, 2009.

[124] A. Aicher, C. Heeschen, K.-I. Sasaki, C. Urbich, A. M. Zeiher, and S. Dimmeler, "Low-energy shock wave for enhancing recruitment of endothelial progenitor cells: a new modality to increase efficacy of cell therapy in chronic hind limb ischemia," Circulation, vol. 114, no. 25, pp. 2823-2830, 2006.

[125] B. Assmus, D. H. Walter, F. H. Seeger et al., "Effect of shock wave-facilitated intracoronary cell therapy on LVEF in patients with chronic heart failure: the CELLWAVE randomized clinical trial," Journal of the American Medical Association, vol. 309, no. 15, pp. 1622-1631, 2013.

[126] X. Liang, Y. Ding, Y. Zhang, H.-F. Tse, and Q. Lian, "Paracrine mechanisms of mesenchymal stem cell-based therapy: current status and perspectives," Cell Transplantation, vol. 23, no. 9, pp. 1045-1059, 2014.

[127] T. Wang, X.-J. Jiang, Q.-Z. Tang et al., "Bone marrow stem cells implantation with $\alpha$-cyclodextrin/MPEG-PCL-MPEG hydrogel improves cardiac function after myocardial infarction," Acta Biomaterialia, vol. 5, no. 8, pp. 2939-2944, 2009.

[128] N. Tano, T. Narita, M. Kaneko et al., "Epicardial placement of mesenchymal stromal cell-sheets for the treatment of ischemic cardiomyopathy; in vivo proof-of-concept study," Molecular Therapy, vol. 22, pp. 1864-1871, 2014.

[129] Q. Zhang, H. Wang, Y.-J. Yang et al., "Atorvastatin treatment improves the effects of mesenchymal stem cell transplantation on acute myocardial infarction: the role of the RhoA/ROCK/ERK pathway," International Journal of Cardiology, vol. 176, no. 3, pp. 670-679, 2014.

[130] Y. Wang, C. Li, K. Cheng et al., "Activation of liver X receptor improves viability of adipose-derived mesenchymal stem cells to attenuate myocardial ischemia injury through TLR4/NFkappaB and Keap-1/Nrf-2 signaling pathways," Antioxidants \& Redox Signaling, vol. 21, no. 18, pp. 2543-2557, 2014.

[131] Z. Zhang, D. Liang, X. Gao et al., "Selective inhibition of inositol hexakisphosphate kinases (IP6Ks) enhances mesenchymal stem cell engraftment and improves therapeutic efficacy for myocardial infarction," Basic Research in Cardiology, vol. 109, article 417, 2014.

[132] D. Han, W. Huang, S. Ma et al., "Ghrelin improves functional survival of engrafted adipose-derived mesenchymal stem cells in ischemic heart through pi3k/akt signaling pathway," BioMed Research International, vol. 2015, Article ID 858349, 12 pages, 2015.

[133] B. Huang, J. Qian, J. Ma et al., "Myocardial transfection of hypoxia-inducible factor- $1 \alpha$ and co-transplantation of mesenchymal stem cells enhance cardiac repair in rats with experimental myocardial infarction," Stem Cell Research \& Therapy, vol. 5, article 22, 2014.

[134] T. Deuse, C. Peter, P. W. M. Fedak et al., "Hepatocyte growth factor or vascular endothelial growth factor gene transfer maximizes mesenchymal stem cell-based myocardial salvage after acute myocardial infarction," Circulation, vol. 120, no. 1, pp. S247-S254, 2009. 

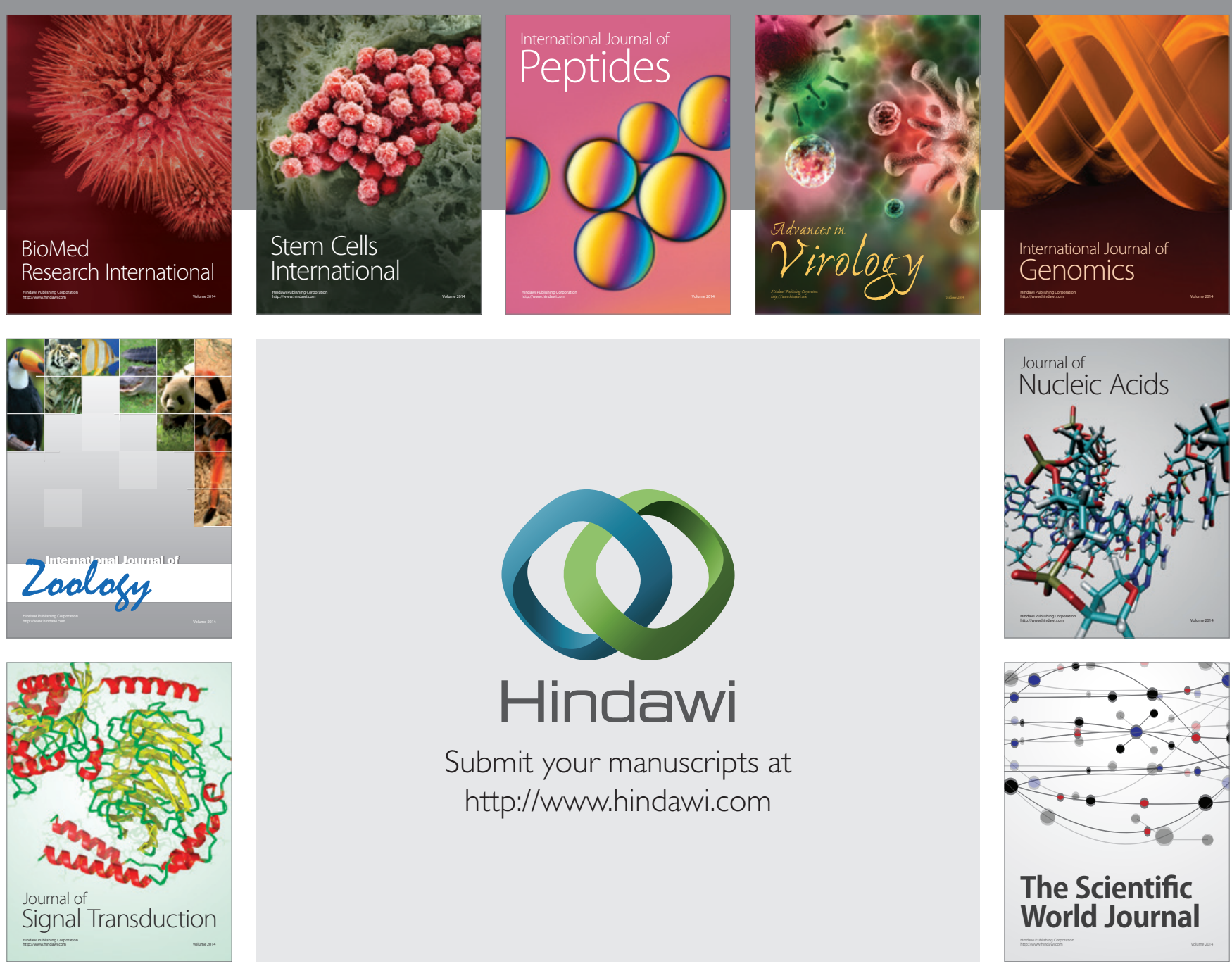

Submit your manuscripts at

http://www.hindawi.com
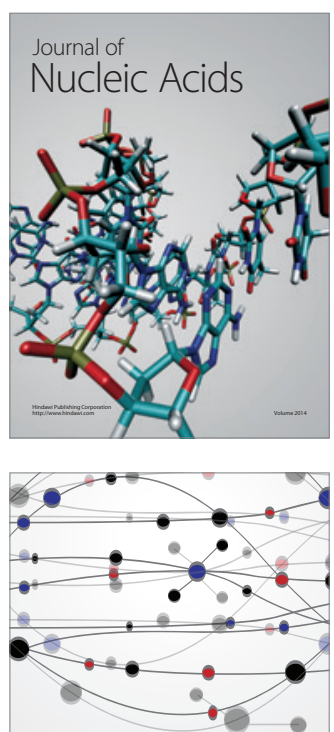

The Scientific World Journal
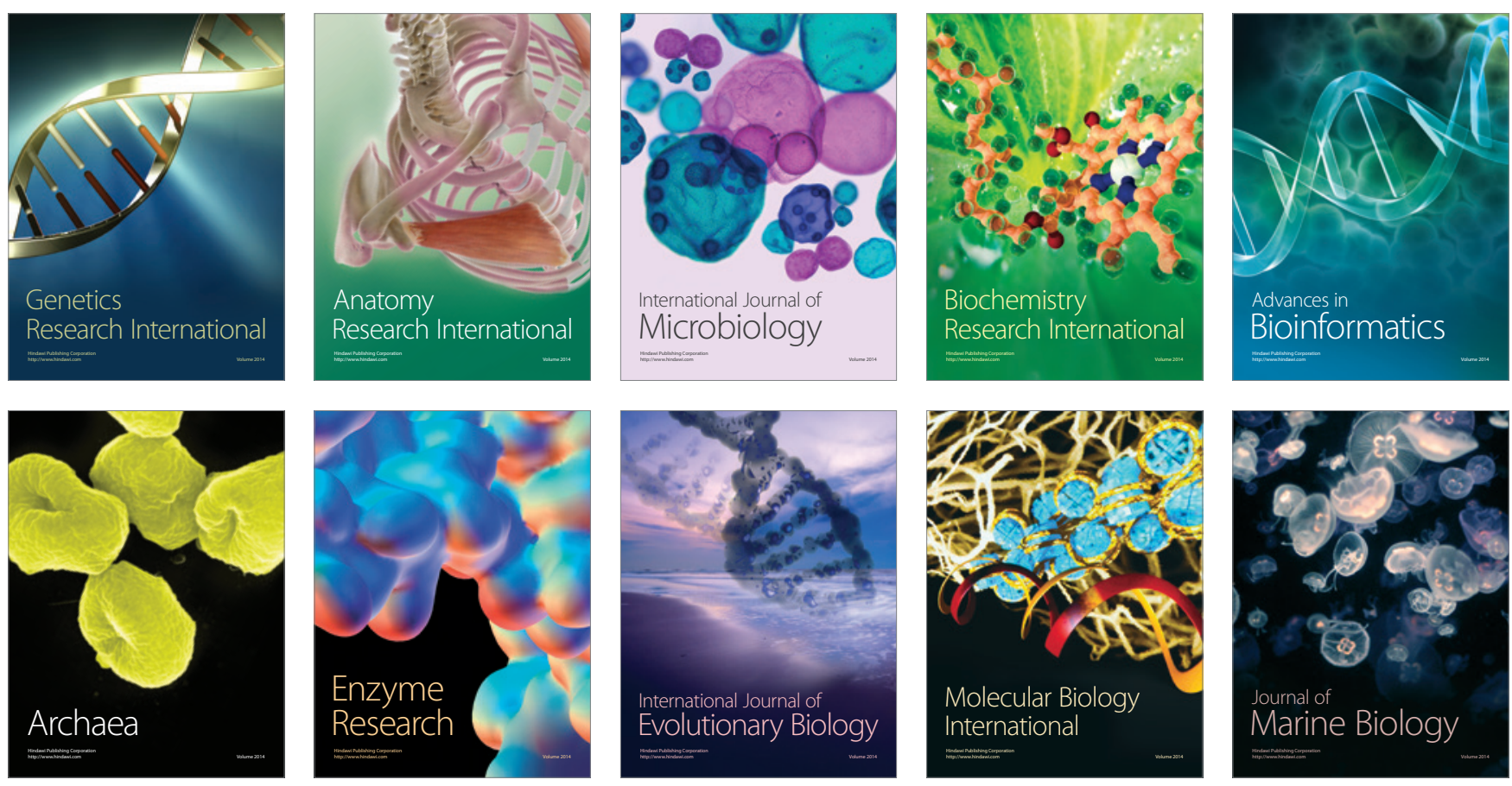